DR JOSE URANGA (Orcid ID : 0000-0003-4656-8569)

PROFESSOR JAKUB FICHNA (Orcid ID : 0000-0002-8443-4417)

DR KULMIRA NURGALI (Orcid ID : 0000-0002-2597-6929)

DR RAQUEL ABALO (Orcid ID : 0000-0002-6726-8795)

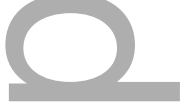

Article type : Original Article<smiles>c1ccc2ccccc2c1</smiles>

\title{
Alterations of colonic sensitivity and gastric dysmotility after acute cisplatin and granisetron
}

\section{Running title: Cisplatin alters colonic sensitivity}

Marta Martín-Ruíz ${ }^{1}$, José A. Uranga ${ }^{2,3,4}$, Paula Mosinska ${ }^{5}$, Jakub Fichna ${ }^{5}$, Kulmira Nurgali ${ }^{6,7,8}, M^{a}$ Isabel Martín-Fontelles ${ }^{2,3,4,9}$, Raquel Abalo ${ }^{2,3,4,9}$ (a)

1 Departamento de Biología, Facultad de Ciencias, Universidad Autónoma de Madrid, Madrid 28049, Spain

2 Departamento de Ciencias Básicas de la Salud, Facultad de Ciencias de la Salud, Universidad Rey Juan Carlos, Alcorcón, Madrid, Spain.

3 Unidad Asociada $1+D+i$ al Instituto de Investigación en Ciencias de la Alimentación, CIAL (CSIC)

4 Grupo de Excelencia Investigadora URJC-Banco de Santander-Grupo Multidisciplinar de Investigación y Tratamiento del Dolor (i+DOL)

${ }^{5}$ Department of Biochemistry, Faculty of Medicine, Medical University of Lodz, Mazowiecka 6/8, 92 -215 Lodz, Poland

${ }^{6}$ College of Health and Biomedicine, Institute for Health and Sport, Victoria University, Melbourne, Australia

${ }^{7}$ Australian Institute for Musculoskeletal Science (AIMSS), Melbourne, Australia

This is the author manuscript accepted for publication and has undergone full peer review but has not been through the copyediting, typesetting, pagination and proofreading process, which may lead to differences between this version and the Version of Record. Please cite this article as doi: $10.1111 /$ nmo.13499

This article is protected by copyright. All rights reserved 
${ }^{8}$ Department of Medicine Western Health, The University of Melbourne, Australia

${ }^{9}$ Unidad Asociada I+D+i al Instituto de Química Médica, IQM (CSIC)

(a) Corresponding author

Departamento de Ciencias Básicas de la Salud

Facultad de Ciencias de la Salud

Universidad Rey Juan Carlos.

Avda. de Atenas s/n.

28922 Alcorcón, Madrid. Spain

Telf: +3491488 8854

Email: raquel.abalo@urjc.es

\section{ABSTRACT}

Background. Cisplatin is a highly emetogenic antineoplastic drug and induces peripheral neuropathy when given in cycles. Granisetron, a $5-\mathrm{HT}_{3}$ antagonist, is clinically used to prevent chemotherapy-induced nausea/emesis and abdominal pain in irritable bowel syndrome. The effects of cisplatin on visceral sensitivity and those of granisetron in the context of cancer chemotherapy are not well known.

Methods. Adult male Wistar rats received two intraperitoneal injections $30 \mathrm{~min}$ apart: granisetron $\left(1 \mathrm{mg} \mathrm{kg}^{-1}\right) /$ vehicle, and cisplatin $\left(6 \mathrm{mg} \mathrm{kg}^{-1}\right) / v$ vehicle. Thereafter, nausea-like behavior was measured as bedding intake for $4 \mathrm{~h}$, and gastric dysmotility was measured radiographically for $8 \mathrm{~h}$. Gastric weight and size were determined ex vivo and samples of the forestomach, corpus, ileum and colon were obtained for histological analysis at 4 and 30 hours after cisplatin/vehicle. Visceral sensitivity was measured as abdominal contractions in response to mechanical intracolonic stimulation $2 \mathrm{~h}$ after cisplatin/vehicle.

Key results. Cisplatin induced bedding intake and gastric dysmotility, and granisetron blocked these effects, which occurred in the absence of frank mucositis. Visceral sensitivity was reduced to a similar extent by both drugs alone or in combination. 
Conclusions \& inferences. Cisplatin-induced bedding intake and gastric dysmotility were blocked by granisetron, confirming the involvement of serotonin acting on $5-\mathrm{HT}_{3}$ receptors. Unexpectedly, visceral sensitivity to colonic distension was reduced, to the same extent, by cisplatin, granisetron and their combination, suggesting important mechanistic differences with nausea and gastric dysmotility that warrant further investigation.

KEYWORDS: cisplatin; granisetron; pica; gastric dysmotility; emesis; visceral sensitivity.

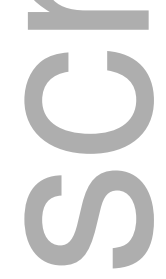

\section{KEY MESSAGES:}

- Antitumoral drugs like cisplatin produce many adverse effects, including those affecting the gastrointestinal tract. Cisplatin is highly emetogenic and provokes neuropathic pain but its effects on colonic sensitivity are less known.

- In rats, acute cisplatin induced nausea-like behavior and decreased gastric motility. Both effects were prevented by the antiemetic drug granisetron. Cisplatin, granisetron or their combination decreased colonic sensitivity to the same extent.

- Cisplatin and granisetron effects on nausea/gastric motility and sensitivity to colonic distension must involve different mechanisms.

\section{INTRODUCTION}

Cancer chemotherapy is associated with the development of numerous and feared adverse effects that may compromise treatment (1). Adverse effects in the gastrointestinal tract include nausea and emesis, as well as diarrhea or constipation, depending on the particular drug (1-5). Cisplatin is a highly emetogenic antitumoral drug, often used as reference in experimental studies 
searching for new antiemetics $(6,7)$. Although other mechanisms may be involved, serotonin released from the enterochromaffin cells and acting upon vagal afferents through $5-\mathrm{HT}_{3}$ receptors, is one of the main components underlying nausea and emesis induced by cisplatin (8-11) and is probably also involved in the effect of other antitumoral drugs. Thus, $5-\mathrm{HT}_{3}$ antagonists are currently used in all moderate to severe emetogenic chemotherapy regimens as key antiemetics (12).

In experimental animals lacking the emetic reflex, like the rat, other markers of nausea/emesis are needed. Pica, the ingestion of non-nutritive substances, like kaolin $(6,13,14)$, occurs in the rat both after a single dose of cisplatin (15), and after its repeated administration (cycles) (16-18). Another effect of antitumoral drugs, tightly related to nausea/emesis, and present in all vertebrate species, is gastric dysmotility. Thus, delayed gastric emptying and gastric distension have been reported to occur after cisplatin administration in the rat $(15,18-22)$. Granisetron and other $5-\mathrm{HT}_{3}$ receptor antagonists are capable of preventing cisplatin-induced acute pica, measured as kaolin intake (20), and gastric dysmotility (21). Interestingly, it has been shown that bedding intake can be used, instead of kaolin intake, to evaluate pica induced by opiates in the rat (23), but, as far as we know, the effect of cisplatin on bedding intake has not been determined, nor the effect of $5-\mathrm{HT}_{3}$ antagonists on this.

Another well-known chemotherapy-induced adverse effect is neuropathic pain, which affects limbs in a so-called "stocking and glove" manner (24). In contrast, the occurrence of visceral pain related to chemotherapy has received less attention. Unlike somatic pain, visceral pain is diffuse, difficult to localize, irradiated to superficial structures and often accompanied by nausea, vomiting and other manifestations (25). Among the $40 \%$ of the population experiencing visceral pain, $28 \%$ corresponds to cancer patients, in whom pain may be associated with metastasis or treatments (25). In this context, visceral pain may be associated with the development of chemotherapy-induced mucositis (27) and enteric neuropathy (28-31), frequent complications of these treatments. However, visceral pain was recently demonstrated to occur in the rat shortly after paclitaxel, another antineoplastic drug (32). Whether or not visceral pain 
develops also immediately after cisplatin treatment is not clear, nor the effect of $5-\mathrm{HT}_{3}$ antiemetics used to prevent chemotherapy-induced gastric dysmotility, nausea and emesis.

Therefore, our aim was to determine if visceral sensitivity is altered after acute cisplatin administration, at a dose capable of inducing kaolin intake and gastric dysmotility in the rat (15). We also investigated if this dose was able to induce bedding intake and evaluated the effect of granisetron on the functional effects and structural changes induced by cisplatin in the gut wall.

\section{MATERIALS AND METHODS}

The experiments were designed and performed in accordance with the European and Spanish legislation on care and use of experimental animals (EU Directive 2010/63/EU for animal experiments; R.D. 53/2013) and were approved by the Ethic Committee at Universidad Rey Juan Carlos (URJC). The animal protocol was designed to minimize pain or discomfort to the animals.

\section{Animals}

Male Wistar rats (290-370 g) were obtained from Charles River (studies on gastrointestinal motility, $n=32$ ) and from the Veterinary Unit at URJC (bedding intake studies, $n=31$; visceral sensitivity, $n=25$ ). Animals were group-housed (3$4 /$ cage) in standard transparent cages $(60 \mathrm{~cm} \times 40 \mathrm{~cm} \times 20 \mathrm{~cm})$, under environmentally controlled conditions (temperature $=20^{\circ} \mathrm{C}$; humidity $=60 \%$ ), with a $12 \mathrm{~h}$ light/12 $\mathrm{h}$ dark cycle. Animals had free access to standard laboratory rat chow (Harlan Laboratories Inc.) and sterile tap water. The animals for the studies on gastrointestinal motility were acclimatized to laboratory conditions for two weeks prior to experimentation.

\section{Drug treatments}

In all cases, animals received 2 intraperitoneal (i.p.) injections, separated by 30 min: the first one was granisetron $\left(1 \mathrm{mg} \mathrm{kg}^{-1}\right)$ or saline $(0.5 \mathrm{ml})$; the second one was cisplatin $\left(6 \mathrm{mg} \mathrm{kg}^{-1}\right)$ or saline $(0.5 \mathrm{ml})$. Thus, treatment groups for the study were: saline+saline $(\mathrm{S}+\mathrm{S})$; saline+cisplatin $(\mathrm{S}+\mathrm{C} 6)$; granisetron+saline (Grani+S); granisetron+cisplatin (Grani+C6). 


\section{Bedding intake as an indirect index of nausea}

After the second drug injection (saline or cisplatin), each rat was placed in an individual cage provided with wood shaving bedding, food and water, and was observed for 4 hours. The number of times the rat ingested bedding in its cage was recorded in periods of 1 hour by a blinded observer.

\section{Analysis of gastrointestinal motor function}

Two kinds of studies were performed to determine the effect of cisplatin and/or granisetron on gastrointestinal motor function: first, radiographic, non-invasive in vivo methods were used to determine alterations in general gastrointestinal transit (see below); second, the weight and size of the stomach were measured ex vivo to more accurately evaluate the alterations produced by the different drugs in gastric motor function. The ex vivo study was performed in two different groups of rats in order to evaluate two different time-points: 4 and $30 \mathrm{~h}$ after cisplatin administration; for ethical reasons, the rats studied at $4 \mathrm{~h}$ were the same used for the bedding intake study and those studied at $30 \mathrm{~h}$ were the same used for the radiographic analysis. All studies were followed by histological analysis (see below).

Radiographic techniques were applied as previously described (15). Thus, 20 min after the second drug injection, $2.5 \mathrm{ml}$ of a suspension of barium sulphate (Barigraph ${ }^{\circledR} A D$, Juste SAQF, Madrid, Spain; $2 \mathrm{~g} \mathrm{ml}^{-1}, \mathrm{t}^{\circ}=22^{\circ} \mathrm{C}$ ) was administered per os. Intragastric gavage administration was carried out with conscious animals, using curved gavage needles appropriate for the animal size (14 gauge, 2.9 inch length, $4 \mathrm{~mm}$ ball diameter). Plain facial radiographs of the gastrointestinal tract were obtained at different time-points (0-8h: T0-T8) after administration of the contrast medium. A CS2100 (Carestream Dental, Spain) digital X-ray apparatus (60 kV, $7 \mathrm{~mA})$ was used, and X-rays were recorded on Carestream Dental T-MAT G/RA film $(15 \times 30 \mathrm{~cm})$ housed in a cassette provided with regular intensifying screen. Exposure time was adjusted to $20 \mathrm{~ms}$ and focus distance was manually fixed to $50 \pm 1 \mathrm{~cm}$. Immobilization of the animals in prone position was achieved by placing them inside adjustable, hand-made, transparent plastic tubes. Habituation to the recording chamber 
prior to commencement of the study did not significantly alter GI motility (15). To further reduce stress, animals were released immediately after each shot (immobilization lasted for less than $2 \mathrm{~min}$ ). A trained investigator blind to the drug administered performed the analysis of the radiographs. Alterations in $\mathrm{Gl}$ motility were semiquantitatively determined from the images by assigning a compounded value to each region of the Gl tract considering the following parameters: percentage of the GI region filled with contrast (0-4); intensity of contrast (0-4); homogeneity of contrast (0-2); and sharpness of the GI region profile (0-2). Each of these parameters was scored and a sum (0-12 points) was made. In addition, the X-rays were scanned and the alterations in the size of stomach and caecum were morphometrically analyzed with the aid of an image analysis system (Image J 1.38 for Windows, National Institute of Health, USA, free software: http://rsb.info.nih.gov/ij/).

For the ex vivo studies at 4 and $30 \mathrm{~h}$ after cisplatin, animals were killed by sharp cervical dislocation and exsanguination, and different organs were removed. For the study of gastric motor function, the stomach was weighed and photographed. The photographs were used to analyze the size of the whole stomach, corpus and forestomach using morphometric methods as described for the X-rays.

\section{Colonic sensitivity}

Two hours after the second drug injection (cisplatin or saline), the rat was sedated with Sedator ${ }^{\circledR}$ (medetomidine hydrochloride, an alpha-2 adrenergic agonist, $1 \mathrm{ml} \mathrm{kg}^{-1}, 1 \mathrm{mg} \mathrm{ml}^{-1}$, i.p.). Once sedated, a $10 \mathrm{~cm}$ longitudinal line was drawn over the linea alba of the rat abdomen, from the penis cranially, and shorter transverse lines were also drawn every $2 \mathrm{~cm}$, to better visualize the contractions during the recordings.

Next, fecal material was gently removed from the rectum and a $5 \mathrm{~cm}$ long latex balloon lubricated with vaseline was inserted through the anus into the colon so that the tip of the balloon was $7 \mathrm{~cm}$ inside the colorectum. The catheter to which the balloon was connected was fixed to the tail of the rat with Parafilm $\AA$, so that during the experiment it could not be expelled. Sedation was reverted with 
Revertor ${ }^{\circledR}$ (atipamezole hydrochloride, an alpha-2 adrenergic antagonist, 0.66 $\mathrm{ml} \mathrm{kg}^{-1}, 5 \mathrm{mg} \mathrm{ml}^{-1}$, i.p.), and the rat was allowed to wake up in the recording cage (it normally took less than 5 min for the rat to wake up and start exploring the cage). After waking up, the rat behavior was recorded using a video camera (iPad, Apple, Madrid, Spain) located $30 \mathrm{~cm}$ below the cage floor. The recording lasted 40 minutes; the first $5 \mathrm{~min}$ were discarded (they were only used to confirm the normal behavior of the rat after recovery from sedation); thereafter, the pressure of the intracolonic balloon was increased, using a sphygmomanometer, from 0 to $75 \mathrm{~mm} \mathrm{Hg}$, in steps of $15 \mathrm{~mm} \mathrm{Hg}$ every 5 minutes, to finally return to $0 \mathrm{~mm} \mathrm{Hg}$ again. Pressure was maintained in each 5 min-interval (tonic stimulation).

For the analysis of visceral sensitivity, the videos were exported as series of frames $\left(1 \mathrm{~s}^{-1}\right)$, using the Free Video to JPG Converter program (v.5.0.73). Each frame was then analyzed to determine the number and duration of contractions, as well as the \% of time spent by the rat contracting the abdomen during each 5-min period. An abdominal contraction was considered as a depression of the abdomen where transverse lines approached one another.

\section{Histopathological analysis of gastrointestinal regions}

Samples were obtained from the stomach (forestomach and corpus), terminal ileum (at least $10 \mathrm{~cm}$ oral to the ileocaecal junction) and distal colon, fixed in buffered $10 \%$ formalin and embedded in paraffin. Sections of $5 \mu \mathrm{m}$ were stained with conventional hematoxylin-eosin (HE). They were studied under a Zeiss Axioskop 2 microscope. The analysis was made in 5-8 random fields per sample measured in 20-40x objective microphotographs with a total of three slices analyzed per specimen. The experimenter was blind to the treatment received by the rat from which the sample under analysis was obtained.

Histological damage of the ileum was evaluated in sections stained with HE using criteria adapted from Galeazzi et al. (33). A numerical score of 0-9 was assigned to each section considering general loss of mucosal architecture (graded 0-3, absent to severe), extent of inflammatory cell infiltrate (graded 03 , absent to transmural), crypt abscess formation ( $0-1$, absent or present), 
goblet cell depletion (0-1, absent or present) and muscular layer thickness (01 , normal to reduced).

The colon was evaluated according to Saccani et al. (34). The numerical score in this case was $0-13$ considering epithelial damage ( $0-3$, normal to severe), infiltration of inflammatory cells (0-4, absence to severe involving submucosa), separation of muscle layer and muscularis mucosae (0-2, normal to severe) and goblet cell depletion (0-4, absent to present).

\section{Compounds and drugs}

Barium sulphate (Barigraf $\AA A D$, Juste $S A Q F$, Madrid, Spain) was suspended in tap water and continuously hand-stirred until administration.

Granisetron hydrochloride (1-methyl-N-(9-methyl-endo-9-azabicyclo[3.3.1]non3-yl-1H-indazole-3-carboxamide monohydrochloride) was obtained from Ascent Scientific (Bristol, UK) and dissolved in saline. Cisplatin (cis-diammineplatinum (II) dichloride) was purchased from Sigma-Aldrich (Spain) and dissolved in saline (sonicated for about $15 \mathrm{~min}$ ).

\section{Statistical analysis}

Data are presented as the mean values \pm SEM (standard error of the mean). Differences between groups were analyzed using unpaired Student's t-test, with Welch's correction where appropriate, or one-way or two-way ANOVA followed by post-hoc Bonferroni multiple comparison test. Values of $p<0.05$ were regarded as being statistically different.

\section{RESULTS}

\section{Bedding intake}

In control (S+S) rats, some bedding intake was observed during the first hour of the study, but this decreased in the remaining observation periods and was not present at all during the third and the fourth hours (Fig. 1). Bedding intake in animals treated with granisetron only $(G r a n i+S)$ was similar to that of control animals all along the 4 hours of the study. In animals treated with cisplatin only $(\mathrm{S}+\mathrm{C} 6)$ bedding intake was always higher than in control animals and the difference was statistically significant during the second hour after cisplatin 
administration. Granisetron administered prior to cisplatin was able to prevent the increase in bedding intake induced by the antineoplastic drug, particularly during the first 2 hours (at this time-point, the difference with S+C6 group was highly significant, but not significant with $S+S$ group), although it overlapped with that of $\mathrm{S}+\mathrm{C} 6$ animals during the third and fourth hours after cisplatin (Fig. 1).

\section{Radiographic study of general gastrointestinal motility}

Gastric emptying in control $(S+S)$ animals was progressive until 4 hours after contrast. At this time-point very little barium remained in the stomach and it decreased even further until the end of the study (Fig. 2A). Granisetron alone (Grani+S) slightly accelerated the motility curve for this organ at T1 and T2 but the effect was significant only at $\mathrm{T} 2$. Cisplatin alone significantly delayed gastric emptying from T2 to T8 and a great amount of barium could still be seen in the stomach of $\mathrm{S}+\mathrm{C} 6$ animals at T8. Administration of granisetron (Grani+C6) prior to cisplatin was able to prevent the effect of cisplatin, and even accelerated gastric emptying at $T 1$, although the motility curve turned to be parallel to that for the $\mathrm{S}+\mathrm{C} 6$ group afterwards and was not statistically different from $\mathrm{S}+\mathrm{S}$ group for the remaining time-points.

Small intestinal transit curve in control animals $(S+S)$ showed a typical filling phase from $T 0$ to $T 1$, a plateau from $T 1$ to $T 2$, and an emptying phase from $T 2$ to T8. The curve for animals treated with granisetron only (Grani+S) showed a similar profile, although the emptying phase tended to be slightly slower and this effect was statistically significant at $\mathrm{T} 4$. In the motility curve for the small intestine of animals treated with cisplatin only $(\mathrm{S}+\mathrm{C} 6)$, which was similar to that in control animals, the plateau was lower. Once again, granisetron was able to prevent the effects of cisplatin on small intestinal transit and the curve reached a plateau similar to that in control animals, but the emptying phase was slightly but significantly slower than those obtained for $\mathrm{S}+\mathrm{S}$ and $\mathrm{S}+\mathrm{C} 6$ animals at T4 (Fig. 2B).

The transit curve for the caecum in control animals showed a typical profile in which barium started to fill the organ at T2 and the maximum contents in this 
organ were reached at T4-T6. Granisetron slightly delayed filling of caecum. The difference in contents with those of $S+S$ animals was significant at T4, although the values obtained for T6 and T8 were similar. The transit curve in S+C6 animals was not different from that in control animals, although the maximum values in T4-T8 were to some extent lower than the corresponding ones in S+S rats. Granisetron delayed filling of caecum even further in animals treated also with cisplatin, although contents at T8 were practically the same as in $\mathrm{S}+\mathrm{S}$ and $\mathrm{S}+\mathrm{C6}$ (Fig. 2C).

In control animals $(S+S)$, barium started to be observed in the colorectal fecal pellets at T4 and reached the maximum at T8. In animals treated with granisetron only $(G r a n i+S)$, barium was seen in the fecal pellets from T6. In cisplatin-treated animals $(S+C 6)$, some filling of colorectum was seen at $\mathrm{T} 4$, but the maximum contents at T8 tended to be lower than in control animals. Granisetron prevented the effects of cisplatin and the transit curves for Grani+C6 animals tended to be similar again to that of control $(S+S)$ animals (Fig. 2D). In any case, differences were not statistically significant among the different treatment groups in this region.

The morphometric study of the stomach and caecum showed similar results to the semiquantitative analysis. Thus, the stomach size (area of the stomach stained with barium) decreased progressively from T0 to T8 in $S+S$ and Grani+S animals. However, in cisplatin-treated animals $(S+C 6)$, there was an initial increase in gastric size from T0 to T1 which stayed enlarged at the following time points. In Grani+C6 animals, gastric size did not increase from T0 to $T 1$, slightly decreased from $T 0$ to $T 6$, and decreased more sharply from $T 6$ to T8; although control values at T6 and T8 were not reached, the difference with S+C6 animals was significant (Fig. 2E, G).

Regarding the caecum, the curve showing the changes in its size (area stained by barium) for control animals $(S+S)$ was very similar to that obtained in the semiquantitative analysis. However, the curves obtained for the other three treatment groups were displaced to the right to a similar extent (the difference 
with control animals being statistically significant for $\mathrm{S}+\mathrm{C} 6$ and Grani+S at T4) and similar sizes were reached at T6-T8 for all groups (Fig. 2F, H).

\section{Ex vivo analysis of stomach weight and size}

Compared to control animals $(S+S)$, cisplatin induced an increase in stomach weight 4 hours after administration. This was accompanied by an increase in stomach size, which was mainly due to an increase in forestomach size (Fig. $3 A-C)$, but not the gastric corpus (data not shown). Granisetron (Grani+S) alone did not significantly alter any of these parameters compared to $S+S$ animals (data not shown), whereas it tended to reduce the effect of cisplatin in all parameters, but the difference reached statistical significance only for stomach weight. Fig. 3D shows representative images of this study.

The results obtained $30 \mathrm{~h}$ after cisplatin were similar to those obtained $4 \mathrm{~h}$ after, when the antineoplastic drug was given alone. However, weight, size of the whole stomach and size of the forestomach tended to increase (not decrease) in Grani+C6 compared to S+C6 (Fig. 3A'-D').

\section{Colonic sensitivity}

Abdominal contractions in response to increasing intracolonic pressure in vivo were analyzed as a measure of visceral sensitivity. The results of this experiment are shown in Figure 4. Control rats showed a progressive increase in the number of contractions and \% of time with abdominal contractions (visceral pain response), as the mechanical stimulus increased, and when the pressure was brought back to zero, no further contractions occurred (Fig 4A, C). The duration of contractions was similar regardless of the pressure capable of producing them (15-75 $\mathrm{mm} \mathrm{Hg}$ ) (Fig 4B).

In rats treated with cisplatin $(\mathrm{S}+\mathrm{C} 6)$, granisetron $(\mathrm{Grani}+\mathrm{S})$ or both $(\mathrm{Grani}+\mathrm{C} 6)$, there was also a progressive increase in the number of abdominal contractions with increasing mechanical stimulation, but the area under the curve tended to be lower than in control rats (Fig 4A). The duration of contractions was similar in all groups in response to increasing pressure (Fig 4B). Regarding the \% of time with abdominal contractions, compared to control rats $(S+S)$, the animals 
treated with only cisplatin $(S+C 6)$ showed values significantly lower at 45,60 and $75 \mathrm{~mm} \mathrm{Hg}$ and those treated with granisetron plus cisplatin (Grani+C6) at 60 and $75 \mathrm{~mm} \mathrm{Hg}$ (Fig 4C).

\section{Histopathological analysis of gastrointestinal regions}

The histological pattern in HE stained sections of the stomach did not demonstrate any relevant change $4 \mathrm{~h}$ after cisplatin treatment compared to control rats. Granisetron did not have any effect and did not alter histology in cisplatin-treated rats either (data not shown).

As shown in Fig. 5 (A-D), at this time-point, ileal samples from cisplatin-treated rats were slightly but significantly damaged when compared to controls. Ileum sections from rats treated with granisetron alone (not shown) or together with cisplatin, scored lower but not significantly different to the sections of the ileum from cisplatin-treated animals and controls. Scores higher than controls in this experiment were mainly due to the presence of inflammatory infiltrates in the mucosa. Regarding the colon (Fig. 5A'-D'), treatment with cisplatin caused an increase in the number and extension of inflammatory infiltrates. The addition of granisetron relieved the effect caused by cisplatin but not significantly.

At $30 \mathrm{~h}$ after cisplatin, some structural damage was observed in the forestomach and at the apical area of the corpus glands after cisplatin treatment and granisetron did not relieve this (Fig 6). Also, exposure to cisplatin was to some extent detrimental to ileal architecture (Fig. 7B, D): some villi appeared damaged and a clear increase in immune cell infiltrations was seen. Granisetron (Fig. 7C, D) did not evoke any improvement in these parameters. Finally, no significant effect of cisplatin, alone or combined with granisetron, was observed in colonic samples (Fig. $7 A^{\prime}-D^{\prime}$ ).

\section{DISCUSSION}

Here we examined the effects of the antineoplastic drug cisplatin and the $5-\mathrm{HT}_{3}$ receptor antagonist granisetron, alone or combined, on gastrointestinal motility and colonic sensitivity in the rat. Cisplatin was used at a dose known to induce pica (a surrogate marker of nausea in non-vomiting species $(6,13-18)$ ) and 
gastric dysmotility (15). Here, both effects were seen: pica, as bedding intake (23); and gastric dysmotility, as reduced gastric emptying and gastric distension in both X-rays and ex vivo. This dose of cisplatin induced only minor histological alterations of the gut wall and not frank mucositis at the time-points evaluated. Granisetron, which is able to prevent kaolin intake (35), prevented also bedding intake and gastric dysmotility occurring shortly (up to $4 \mathrm{~h}$ ) after cisplatin administration. In contrast, both drugs, alone or combined, reduced to a similar extent the number of the abdominal contractions produced in the rat in response to mechanical stimulation of the colon.

Cisplatin is a highly emetogenic drug (36) and often used in the search for new antiemetics (7). In rodents, which are the most commonly used laboratory animals, indirect markers of nausea/vomiting need to be used because they lack the motor limb of the emetic reflex. In rats, these indirect markers include paired taste avoidance (37), gaping (38), changes in facial expression (39) and pica $(13,23)$. Pica has been shown to be induced after both single $(14,15)$ and repeated administration of cisplatin (16-18). Pica, measured here as bedding intake, was particularly intense 1-2 hours after cisplatin, and granisetron was able to reduce this behavior which is consistent with previously reported block of cisplatin-induced kaolin intake $(35,40)$. Thus, bedding intake recording provides an easy, non-sophisticated and non-stressful method (the absence of bedding in the cage, often removed in kaolin intake experiments, is stressful for rodents) to evaluate the immediate effect of emetogenic stimuli like opiates (23) and cisplatin (present report), and it might prove useful to evaluate other emetogenic stimuli like rotation (41) or abdominal radiation (43).

Emetogenic stimuli also induce gastric dysmotility. This has been used as an indirect marker of nausea in rodents $(20,21,43)$ but occurs likewise in nonrodent species $(44,45)$. Similar to previous reports $(15,20,21,46)$, our study demonstrated that cisplatin at $6 \mathrm{mg} \mathrm{kg}^{-1}$ reduced gastric emptying and produced gastric distension, mainly due to the distension of the forestomach. Gastric dysmotility associated to this high dose of cisplatin was observed as soon as 20 min after administration (21) and lasted for at least 3 days (15). 
Granisetron blocked cisplatin-induced bedding intake and gastric dysmotility, mainly during the first two hours after administration. Immediately after administration, cisplatin induces the massive release of serotonin from the enterochromaffin cells $(10,47)$ and this effect directly accounts for gastric dysmotility (48). The serotonin receptors involved in this immediate effect of cisplatin, located on vagal afferents innervating the upper gastrointestinal tract, are mainly of the $5-\mathrm{HT}_{3}$ type, and thus granisetron and other antiemetics sharing the same mechanism of action are useful to prevent this effect, facilitate gastric emptying and block gastric (forestomach) distension (21).

Granisetron did not prevent gastric dysmotility at $30 \mathrm{~h}$ after cisplatin. The relatively short-lasting gastroprokinetic effect of granisetron seen here is probably mainly due to its short half-life (in rats, only $0.7 \mathrm{~h}$ after iv administration $(49,50))$. However, it is important to note that, at a later stage after cisplatin administration, other mechanisms of action take place $(44,51)$, including the release of other neurotransmitters (like substance $\mathrm{P}$ ) and even pro-inflammatory mediators, thus making $5-\mathrm{HT}_{3}$ antagonists less efficacious to control delayed emesis (52), delayed pica (35) and delayed gastric dysmotility (20), even when repeated administration or extended-release formulations are used (53). Furthermore, upon cyclic use of cisplatin, $5-\mathrm{HT}_{3}$ antagonists may lose efficacy $(21,54)$. These facts justify the search for new antiemetics $(4,7)$.

Even though we used a high dose of cisplatin with profound effects on gastric motility, and despite the fact that serotonin released from the enterochromaffin cells may contribute itself to triggering intestinal inflammation (55), very little structural damage was found at 4 and $30 \mathrm{~h}$ after treatment, and this was mainly associated with an increased occurrence of lymphoid nodules in the intestinal regions, particularly in the ileum. Damage was found in the forestomach and at the apical part of some glands in the corpus only $30 \mathrm{~h}$ after cisplatin administration, suggesting that, at that time-point (but not at T4), cisplatin had already triggered apoptosis and inhibition of cell proliferation in this tissue (56, 57). lleum was more consistently sensitive to cisplatin, but damage scores obtained in both ileum and colon, although significant in some cases, were relatively low. Thus, cisplatin-induced immediate gastric dysmotility might be 
related to the presence of some early inflammatory reactions (mainly lymphoid nodule activation), occurring as soon as 4 hours after cisplatin administration, but not to the presence of frank mucositis, which may need more time to develop (28). Although granisetron blocked cisplatin-induced early gastric dysmotility (and bedding intake), it did not clearly protect against nor clearly increased any of these damaging effects of cisplatin on the gut wall, suggesting that they might be due to serotonin-independent mechanisms.

In contrast to somatic neuropathy, not much is known about the effects of cancer chemotherapy on visceral sensitivity, particularly in experimental animals. In a recent study (32), paclitaxel intraperitoneally administered dosedependently induced visceral pain in the rat up to $100 \mathrm{~min}$ after administration. The presence of writhing responses was used as a marker of spontaneous visceral pain. Writhing responses were not observed in our bedding intake experiments (lasting for 4 hours after cisplatin), suggesting that, in contrast to paclitaxel, intraperitoneal cisplatin does not induce immediate spontaneous abdominal pain.

Thus, we evaluated the effects of cisplatin on abdominal pain in response to colonic mechanical stimulation. In all groups of animals, the number of abdominal contractions increased in a pressure-dependent manner. Importantly, abdominal contractions had a fairly homogeneous duration of 1.3$1.7 \mathrm{~s}$, suggesting that abdominal muscle motor function itself was not altered by treatments. However, animals treated with cisplatin, granisetron, or both showed a lower response (significant for $\%$ of time with abdominal contractions) than control $(\mathrm{S}+\mathrm{S})$ animals, suggesting that both drugs inhibited colonic sensitivity to mechanical stimulation. Interestingly, in rats subjected to colonic mechanical stimulation, cisplatin and granisetron effects on gastric weight and size were maintained (data obtained ex vivo after the visceral pain experiment, not shown).

Cisplatin alone did not increase but inhibited colonic sensitivity to mechanical stimulation. Although time-points after cisplatin administration for visceral pain assessment and histology were not exactly the same (studies were performed 
2.5-3.5 $\mathrm{h}$ and $4 \mathrm{~h}$ after cisplatin, respectively), it could be speculated that the increased lymphoid nodules found in cisplatin-treated animals, in the absence of frank mucositis, have an anti-inflammatory (and not a pro-inflammatory) role in the few hours after administration. However, in a previous report (58), acute intraduodenally applied serotonin attenuated the visceromotor response to colorectal distension, in a manner sensitive to both granisetron and the cannabinoid receptor 1 (CB1) antagonist AM251. It was suggested that serotonin activated vagal $5-\mathrm{HT}_{3}$ receptors in the duodenum, leading to the duodenal release of anandamide which reduced pain through activation of CB1 receptors. Interestingly, activation of $\mathrm{CB} 1$ receptors suppresses gastric emptying and intestinal transit (59), and inactivation of CB1 receptors with AM251 improved gastric dysmotility induced by vincristine (60) and cisplatin (data not shown). Therefore, although other mechanisms cannot be discarded, serotonin-induced anandamide release and activation of CB1 receptors might reduce visceral pain (and induce gastric dysmotility) in the few hours after cisplatin.

Granisetron alone tended to reduce abdominal contractions in response to tonic mechanical stimulation, particularly at the high pressures used. Furthermore, in animals treated with both granisetron and cisplatin, gastric dysmotility was corrected, but inhibition of visceral pain was maintained (and filling of caecum was even further delayed). In these animals, a different mechanism, other than duodenal serotonin release and vagal $5-\mathrm{HT}_{3}$ receptors activation, must be involved in visceral pain inhibition. Recently, $5-\mathrm{HT}_{3}$ receptors were demonstrated to be involved in abdominal pain transmission within the ventrolateral medulla, occurring in response to noxious colorectal distension (61). Although the origin of serotonin released in those experiments was not determined, in conditions of colonic hypersensitization, like irritable bowel syndrome (IBS), serotonin may be released from intestinal mast cells, contributing to abdominal pain (62). This underlies the analgesic effect of $5-\mathrm{HT}_{3}$ antagonists in IBS, with increased intestinal transit time (also seen here) and constipation as their main adverse effects (63), and might also be involved in granisetron effects (alone or combined with cisplatin) on colonic sensitivity. 
In conclusion, cisplatin (at a dose able to induce gastric dysmotility) and granisetron (at a dose able to counteract cisplatin-induced gastric dysmotility and nausea-like behavior), alone or combined, were able to reduce colonic sensitivity to tonic mechanical stimulation, suggesting important mechanistic differences with nausea and gastric dysmotility that warrant further investigation.

\section{CONFLICT OF INTEREST}

The authors declare that the research was conducted in the absence of any commercial or financial relationships that could be construed as a potential conflict of interest.

\section{AUTHOR CONTRIBUTIONS}

RA designed the study. MMR and PM performed the experiments. MMR analyzed the data. MMR, JAU and RA wrote the manuscript. MIMF contributed financial support. MIMF, KN and JF contributed essential intellectual input. All authors reviewed and approved the final version of the manuscript.

\section{ACKNOWLEDGEMENTS}

The authors are grateful to Laura Núñez, Maica Merino and Lorena Blanco for technical assistance in collecting functional data, and to Raquel Franco, Julio Paredes and Antonio Márquez, for histological processing of tissues.

\section{FUNDING}

Ministerio de Ciencia e Innovación (SAF2012-40075-C02-01). L. Blanco had a contract by Consejería de Educación, Juventud y Deporte from Comunidad de Madrid and Fondo Social Europeo (PEJ15/BIO/TL-0580).

\section{FIGURE LEGENDS}


Figure 1. Effect of acute administration of granisetron and/or cisplatin on bedding intake after drug administration. Animals received two intraperitoneal (i.p.) administrations $30 \mathrm{~min}$ apart. The first one was granisetron (Grani, $1 \mathrm{mg}$ $\left.\mathrm{kg}^{-1}\right)$ or saline $\left(\mathrm{S}, 1 \mathrm{ml} \mathrm{kg}^{-1}\right)$. The second one was $\mathrm{S}$ or cisplatin $\left(6 \mathrm{mg} \mathrm{kg}^{-1}, \mathrm{C} 6\right)$. Animals were placed into individual cages, provided with food, water and wood shaving bedding. Acute bedding intake (indirect index of nausea) was recorded as the number of times each rat ate the bedding in its cage every hour for 4 hours. Values represent mean $\pm \mathrm{SEM}$ ( $\mathrm{n}=6-7$ all groups). ${ }^{* * *} p<0.001$ vs $\mathrm{S}+\mathrm{S}$; \#\#\# $p<0.001$ vs $S+C 6$.

Figure 2. Effect of cisplatin and/or granisetron on general gastrointestinal motor function and on size of stomach and caecum in the rat. General gastrointestinal transit was assessed using radiographic methods in: A. Stomach (gastric emptying); B. Small intestine; C. Caecum; D. Colorectum. Animals received two intraperitoneal (i.p.) administrations $30 \mathrm{~min}$ apart. The first one was saline (S, 1 $\mathrm{ml} \mathrm{kg}{ }^{-1}$ ) or granisetron (Grani, $1 \mathrm{mg} \mathrm{kg}^{-1}$ ). The second one was $\mathrm{S}$ or cisplatin (6 $\left.\mathrm{mg} \mathrm{kg}^{-1}, \mathrm{C} 6\right)$. Barium sulphate $\left(2.5 \mathrm{ml}^{2} 2 \mathrm{~g} \mathrm{ml}^{-1}\right)$ was gavaged after cisplatin or saline. The size of stomach $(E)$ and caecum $(F)$ was evaluated using Image $J$ (see text for details). Values represent mean $\pm \operatorname{SEM}(n=8$, all

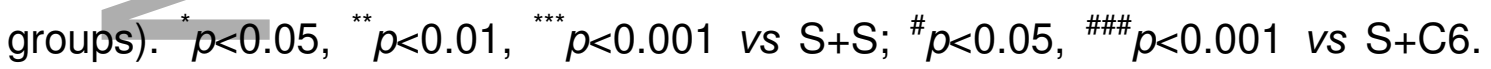
Two-way ANOVA followed by Bonferroni post-hoc test. $G$ and $H$ show representative images of animals treated with $\mathrm{S}+\mathrm{S}$, Grani+S, $\mathrm{S}+\mathrm{C} 6$ or $\mathrm{Grani+} 66$ (left to right, respectively), $4(\mathrm{G})$ and $8(\mathrm{H}) \mathrm{h}$ after contrast administration. Scale bar: $3 \mathrm{~cm}$.

Figure 3. Effect of acute administration of granisetron and/or cisplatin on stomach weight, whole stomach size and forestomach size in the rat. Animals received two intraperitoneal (i.p.) administrations $30 \mathrm{~min}$ apart. The first one was saline $\left(S, 1 \mathrm{ml} \mathrm{kg}^{-1}\right)$ or granisetron (Grani, $1 \mathrm{mg} \mathrm{kg}^{-1}$ ). The second one was of $S$ or cisplatin $\left(6 \mathrm{mg} \mathrm{kg}^{-1}, \mathrm{C} 6\right)$. Stomachs were obtained 4 (upper panel) or 30 $\mathrm{h}$ (lower panel) later for measurement of weight and size. Size was measured using Image J (see text for details). A, A': Stomach weight. B, B': Whole stomach size (area). C, C': Forestomach size (area). D, D': Representative images of stomachs from animals treated with $S+S\left(a, a^{\prime}\right), S+C 6\left(b, b^{\prime}\right)$, 
Grani+C6 (c, c'). Values represent mean $\pm \operatorname{SEM}(n=8$, all groups). " $p<0.05,{ }^{* *} p<0.01,{ }^{* * *} p<0.001$ vs $S+S$; ${ }^{*} p<0.05$ vs $S+C 6$. One-way ANOVA followed by Bonferroni post-hoc test. Ruler: in $\mathrm{cm}$.

Figure 4. Effect of acute administration of granisetron and/ or cisplatin on abdominal contractions in response to mechanical intracolonic stimulation in the rat. Animals received two intraperitoneal (i.p.) administrations $30 \mathrm{~min}$ apart. The first one was granisetron (Grani, $1 \mathrm{mg} \mathrm{kg}^{-1}$ ) or saline $\left(\mathrm{S}, 1 \mathrm{ml} \mathrm{kg}^{-1}\right)$. The second one was $\mathrm{S}$ or cisplatin $\left(6 \mathrm{mg} \mathrm{kg}^{-1}, \mathrm{C} 6\right)$. A balloon was inserted into the colon of the rat, and was connected to a sphygmomanometer, through which pressure was increased in steps of $15 \mathrm{~mm} \mathrm{Hg}$ every 5 minutes, 2 hours after the administration of the drugs. A. Number of abdominal contractions; B. Duration of abdominal contractions; $\mathrm{C}$. Percentage of time with abdominal contractions. Values represent mean \pm SEM ( $n=6-7$ each group). " $p<0.05,{ }^{* *} p<0.01$, vs $S+S$. Two-way ANOVA followed by Bonferroni post-hoc test.

Figure 5. Effect of acute administration of granisetron and/or cisplatin on histological appearance of gut wall $4 \mathrm{~h}$ after cisplatin administration in the rat. Animals received two intraperitoneal (i.p.) administrations $30 \mathrm{~min}$ apart. The first one was granisetron (Grani, $1 \mathrm{mg} \mathrm{kg}^{-1}$ ), or saline $\left(\mathrm{S}, 1 \mathrm{ml} \mathrm{kg}^{-1}\right)$. The second one was $S$ or cisplatin $\left(6 \mathrm{mg} \mathrm{kg}^{-1}, \mathrm{C} 6\right)$. Samples were obtained $4 \mathrm{~h}$ later for conventional histological analysis. Representative images of sections stained with hematoxylin-eosin (HE) from ileum (upper panel, A-C, scale bar: $200 \mu \mathrm{m}$ ) and colon (lower panel, A'-C', scale bar: $400 \mu \mathrm{m}$ ) are shown. Results of the semiquantitative analysis of the histological sections are shown in $D$ (ileum) and D' (colon). A, A' (and white bar in D, D'): control animals treated with S+S. B, B' (and red bar in D, D'): animals treated with S+C6. C, C' (and blue bar in D, D'): animals treated with Grani+C6. Dotted horizontal lines in D and D' represent maximum values for histological damage in each tissue. Values represent mean $\pm \operatorname{SEM}\left(n=8\right.$, all groups). ${ }^{*} p<0.05,{ }^{* *} p<0.01$ vs $S+S$. One-way ANOVA followed by Bonferroni post-hoc test. Scale bar: 200 (ileum) and $400 \mu \mathrm{m}$ (colon). Arrows indicate inflammatory nodules. 
Figure 6. Effect of acute administration of granisetron and/or cisplatin on histological appearance of stomach wall $30 \mathrm{~h}$ after cisplatin administration in the rat. Animals received two intraperitoneal (i.p.) administrations $30 \mathrm{~min}$ apart. The first one was saline $\left(\mathrm{S}, 1 \mathrm{ml} \mathrm{kg}^{-1}\right)$ or granisetron (Grani, $1 \mathrm{mg} \mathrm{kg}^{-1}$ ). The second one was $\mathrm{S}$ or cisplatin (6 mg kg-1, $\mathrm{C} 6$ ). Samples were obtained $30 \mathrm{~h}$ later for conventional histological analysis. Representative images of sections stained with hematoxylin-eosin (H-E) from the corpus (upper panel, A-C, scale bar: 400 $\mu \mathrm{m}$ ) and forestomach (lower panel, $A^{\prime}-C^{\prime}$, scale bar: $400 \mu \mathrm{m}$ ) are shown. Control animals treated with $S+S: A, A^{\prime}$. Animals treated with $S+C 6: B, B^{\prime}$. Animals treated with Grani+C6: C, C'. Scale bar: 200 and $400 \mu \mathrm{m}$ (corpus and forestomach, respectively).

Figure 7. Effect of acute administration of granisetron and/or cisplatin on histological appearance of gut wall $30 \mathrm{~h}$ after cisplatin administration in the rat. Animals received two intraperitoneal (i.p.) administrations $30 \mathrm{~min}$ apart. The first one was of granisetron (Grani, $1 \mathrm{mg} \mathrm{kg}^{-1}$ ), or saline $\left(\mathrm{S}, 1 \mathrm{ml} \mathrm{kg}^{-1}\right)$. The second one was $\mathrm{S}$ or cisplatin $\left(6 \mathrm{mg} \mathrm{kg}^{-1}, \mathrm{C} 6\right)$. Samples were obtained $30 \mathrm{~h}$ later for conventional histological analysis. Representative images of sections stained with hematoxylin-eosin (HE) from the ileum (upper panel, A-C) and colon (lower panel, $\left.A^{\prime}-C^{\prime}\right)$ are shown. Results of the semiquantitative analysis of the histological sections are shown in D (ileum) and D' (colon). A, A' (and white bar in $D, D^{\prime}$ ): control animals treated with $S+S . B, B^{\prime}$ (and red bar in $D, D^{\prime}$ ): animals treated with S+C6. C, C' (and blue bar in D, D'): animals treated with Grani+C6. Dotted lines in $D$ and $D$ ' represent maximum values for histological damage in each tissue. Values represent mean \pm SEM ( $n=8$, all groups). " $p<0.05,{ }^{* *} p<0.01$ $v s \mathrm{~S}+\mathrm{S}$. One-way ANOVA followed by Bonferroni post-hoc test. Scale bar: 400 $\mu \mathrm{m}$. Arrows indicate inflammatory nodules. 


\section{REFERENCES}

1. Nurgali, K., Jagoe, R. T., Abalo, R., eds. (2018). Adverse Effects of Cancer Chemotherapy: Anything New to Improve Tolerance and Reduce Sequelae? Lausanne: Frontiers Media [DOI: 10.3389/978-2-88945-4822].

2. Sharma R, Tobin P, Clarke SJ. Management of chemotherapy-induced nausea, vomiting, oral mucositis, and diarrhoea. Lancet Oncol 2005; 6: 93-102 [DOI: 10.1016/S1470-2045(05)01735-3].

3. Navari RM. Management of chemotherapy-induced nausea and vomiting: focus on newer agents and new uses for older agents. Drugs 2013; 73: 249-262 [DOI: 10.1007/s40265-013-0019-1].

4. Rapoport BL. Delayed Chemotherapy-Induced Nausea and Vomiting: Pathogenesis, Incidence, and Current Management. Front. Pharmacol 2017; 8:19. [DOI: 10.3389/fphar.2017.00019].

5. McQuade RM, Stojanovska V, Abalo R, Bornstein JC, Nurgali K. Front. Chemotherapy-Induced Constipation and Diarrhea: Pathophysiology, Current and Emerging Treatments. Front Pharmacol 2016;7:414 [DOI: 10.3389/fphar.2016.00414].

6. Liu YL, Malik N, Sanger GJ, Friedman MI, Andrews PL. Pica-a model of nausea? Species differences in response to cisplatin. Physiol Behav 2005; 85: 271-277 [DOI:10.1016/j.physbeh.2005.04.009].

7. Rudd JA, Ngan MP, Lu Z, Higgins GA, Giuliano C, Lovati E, Pietra C.. Profile of Antiemetic Activity of Netupitant Alone or in Combination with Palonosetron and Dexamethasone in Ferrets and Suncus murinus (House Musk Shrew) Front Pharmacol 2016. 7:263. [DOI: 10.3389/fphar.2016.00263].

8. Navari- RM. 5-HT3 receptors as important mediators of nausea and vomiting due to chemotherapy. Biochim Biophys Acta 2015; 1848: 27382746 [DOI: 10.1016/j.bbamem.2015.03.020].

9. Fukui H, Yamamoto M, Sasaki S, Sato S. Involvement of 5-HT3 receptors and vagal afferents in copper sulfate- and cisplatin-induced emesis in monkeys. Eur J Pharmacol 1993; 249: 13-18.

10. Minami M, Endo T, Hirafuji M, Hamaue N, Liu Y, Hiroshige T, Nemoto M, Saito $\mathrm{H}$, Yoshioka M. Pharmacological aspects of anticancer drug- 
induced emesis with emphasis on serotonin release and vagal nerve activity. Pharmacol Ther 2003; 99: 149-165 [DOI: 10.1016/S01637258(03)00057-3].

11. de Jonghe BC, Horn CC. Chemotherapy-induced pica and anorexia are reduced by common hepatic branch vagotomy in the rat. Am J Physiol Regul Integr Comp Physiol 2008; 294: 756-765 [DOI: 10.1152/ajpregu.00820.2007].

12. Rojas C, Raje M, Tsukamoto T, Slusher BS. Molecular mechanisms of 5$\mathrm{HT}(3)$ and $\mathrm{NK}(1)$ receptor antagonists in prevention of emesis. Eur $\mathrm{J}$ Pharmacol 2014; 722: 26-37 [DOI: 10.1016/j.ejphar.2013.08.049].

13. Takeda N, Hasegawa S, Morita M, Matsunaga T. Pica in rats is analogous to emesis: an animal model in emesis research. Pharmacol Biochem Behav 1993; 45: 817-21.

14. Yamamoto K, Nakai M, Nohara K, Yamatodani A. The anti-cancer druginduced pica in rats is related to their clinical emetogenic potential. Eur $J$ Pharmacol 2007; 554: 34-39 [DOI: 10.1016/j.ejphar.2006.09.058].

15. Cabezos PA, Vera G, Castillo M, Fernández-Pujol R, Martín MI, Abalo R. Radiological study of gastrointestinal motor activity after acute cisplatin in the rat. Temporal relationship with pica. Auton Neurosci 2008;141: 54-65. [DOI: 10.1016/j.autneu.2008.05.004].

16. Vera G, Chiarlone A, Martín MI, Abalo R. Altered feeding behaviour induced by long-term cisplatin in rats. Auton Neurosci 2006;126-127:8192.

17. Vera G, Chiarlone A, Cabezos PA, Pascual D, Martín MI, Abalo R. WIN 55,212-2 prevents mechanical allodynia but not alterations in feeding behaviour induced by chronic cisplatin in the rat. Life Sci 2007; 19;81(6):468-79.

18. Cabezos PA, Vera G, Martín-Fontelles MI, Fernández-Pujol R, Abalo R. Cisplatin-induced gastrointestinal dysmotility is aggravated after chronic administration in the rat. Comparison with pica. Neurogastroenterol Motil 2010; 22: 797-805 [DOI: 10.1111/j.1365-2982.2010.01483.x].

19. Viana-Cardoso KV, da Silva MT, Júnior RC, Peixoto Junior AA, Pinho LG, Santos AA, Ribeiro RA, Rola FH, Gondim Fde A. Repeated cisplatin treatments inhibit gastrointestinal motility and induces baroreflex 
changes and mechanical hyperalgesia in rats. Cancer Invest 2011; 29: 494-500 [DOI: 10.3109/07357907.2011.597814].

20. Malik NM, Liu YL, Cole N, Sanger GJ, Andrews PL. Differential effects of dexamethasone, ondansetron and a tachykinin NK1 receptor antagonist (GR205171) on cisplatin-induced changes in behaviour, food intake, pica and gastric function in rats. Eur J Pharmacol 2007; 555: 164-173 [DOI: 10.1016/j.ejphar.2006.10.043].

21. Vera G, López-Pérez AE, Martínez-Villaluenga M, Cabezos PA, Abalo R. $X$-ray analysis of the effect of the 5-HT3 receptor antagonist granisetron on gastrointestinal motility in rats repeatedly treated with the antitumoral drug cisplatin. Exp Brain Res 2014;232: 2601-2612 [DOI: 10.1007/s00221-014-3954-5]

22. Shi J. Evaluating the various phases of cisplatin-induced emesis in rats. Oncol Lett. 2014;8:2017-2022 [DOI:10.3892/ol.2014.2506].

23. Batra VR, Schrott LM. Acute oxycodone induces the pro-emetic pica response in rats. J Pharmacol Exp Ther 2011; 339: 738-745 [DOI: 10.1124/jpet.111.183343].

24. Kerckhove N, Collin A, Condé S, Chaleteix C, Pezet D, Balayssac D. Long-Term Effects, Pathophysiological Mechanisms, and Risk Factors of Chemotherapy-Induced Peripheral Neuropathies: A Comprehensive Literature Review. Front. Pharmacol 2017;24;8:86. [DOI: 10.3389/fphar.2017.00086].

25. Bielefeldt K, Christianson JA, Davis BM. Basic and clinical aspects of visceral sensation: transmission in the CNS. Neurogastroenterol Motil 2005;17:488-99.

26. Cerveró F. Visceral hyperalgesia revisited. Lancet. 2000;356:1127-8.

27. Cinausero M, Aprile G, Ermacora P, Basile D, Vitale MG, Fanotto V, Parisi G, Calvetti L, Sonis ST. New Frontiers in the Pathobiology and Treatment of Cancer Regimen-Related Mucosal Injury. Front. Pharmacol 2017; 8: 354. [DOI: 10.3389/fphar.2017.00354].

28. Vera G, Castillo M, Cabezos PA, Chiarlone A, Martín MI, Gori A, Pasquinelli G, Barbara G, Stanghellini V, Corinaldesi R, De Giorgio R, Abalo $R$. Enteric neuropathy evoked by repeated cisplatin in the rat. 
Neurogastroenterol Motil 2011; 23(4): 370-8, e162-3. [DOI: 10.1111/j.1365-2982.2011.01674.x].

29. Uranga JA, García-Martínez JM, García-Jiménez C, Vera G, MartínFontelles MI, Abalo R. Alterations in the small intestinal Wall and motoer function after repeated cisplatin in the rat. Neurogastroenterol Motil 2017; 29(7). [DOI: 10.1111/nmo.13047].

30. Wafai L, Taher M, Jovanovska V, Bornstein JC, Dass CR, Nurgali K. Effects of oxaliplatin on mouse myenteric neurons and colonic motility. Front Neurosci 2013; 7: 30. [DOI: 10.3389/fnins.2013.00030].

31. McQuade R, Stojanovska V, Stavely R, Timpani C, Peterson AC, Abalo R, Bornstein JC, Rybalka E, Nurgali K. Oxaliplatin-induced enteric neuronal loss and gastrointestinal dysfunction is prevented by cotreatment with BGP-15. Br J Pharmacol 2018; 175(4):656-677.

32. Rossato MF, Rigo FK, Oliveira SM, Guerra GP, Silva CR, Cunha TM, Gomez MV, Ferreira J, Trevisan G. Participation of transient receptor potential vanilloid 1 in paclitaxel-induced acute visceral and peripheral nociception in rodents. Eur $J$ Pharmacol 2018;828:42-51. [DOI: 10.1016/j.ejphar.2018.03.033].

33. Galeazzi F, Blennerhassett PA, Qiu B, O'Byrne PM, Collins SM. Cigarette smoke aggravates experimental colitis in rats. Gastroenterology 1999; 117: 877-883.

34. Saccani F, Anselmi L, Jaramillo I, Bertoni S, Barocelli E, Sternini C. Protective role of $\mu$ opioid receptor activation in intestinal inflammation induced by mesenteric ischemia/reperfusion in mice. J Neurosci Res 2012;90: 2146-2153 [DOI: 10.1002/jnr.23108].

35. Yamamoto K, Asano K, Tasaka A, Ogura Y, Kim S, Ito Y, Yamatodani A. Involvement of substance $\mathrm{P}$ in the development of cisplatin-induced acute and delayed pica in rats. $\mathrm{Br} J$ Pharmacol 2014;171:2888-2899 [DOl: 10.1111/bph.12629].

36. Herrstedt J, Roila F, Warr D, Celio L, Navari RM, Hesketh PJ, Chan A, Aapro MS. 2016 Updated MASCC/ESMO Consensus Recommendations: Prevention of Nausea and Vomiting Following High Emetic Risk Chemotherapy. Support Care Cancer 2017;25:277-288. [DOI 10.1007/s00520-016-3313-0]. 
37. Parker LA, Rana SA, Limebeer CL. Conditioned nausea in rats: assessment by conditioned disgust reactions, rather than conditioned taste avoidance. Can J Exp Psychol 2008;62:198-209.

38. Parker LA. Conditioned flavor avoidance and conditioned gaping: rat models of conditioned nausea. Eur J Pharmacol 2014;722:122-33. [DOI: 10.1016/j.ejphar.2013.09.070].

39. Yamamoto K, Tatsutani S, Ishida T. Detection of Nausea-Like Response in Rats by Monitoring Facial Expression. Front. Pharmacol 2017; 7:534. [DOI: 10.3389/fphar.2016.00534].

40. Yamamoto K, Asano K, Matsukawa N, Imaizumi M, Yamatodani A. Timecourse analysis of pica in rats using an automatic feeding monitoring system. J Pharmacol Toxicol Methods 2011;63:30-4. [DOI: 10.1016/j.vascn.2010.04.011].

41. Mitchell D, Laycock JD, Stephens WF. Am J Clin Nutr. Motion sicknessinduced pica in the rat. Am J Clin Nutr 1977;30:147-50.

42. Yamamoto K, Takeda N, Yamatodani A. Establishment of an animal model for radiation-induced vomiting in rats using pica. J Radiat Res 2002;43:135-41.

43. Ando K, Takagi K, Tsubone $\mathrm{H}$. Enhanced gastric retention of solid resin beads as a marker for emetic potential of agents in rats. J Toxicol Sci 2012;37: 549-553 [DOI: 10.2131/jts.37.549].

44. Ando H, Mochiki E, Ohno T, Yanai M, Toyomasu Y, Ogata K, Tabe Y, Aihara $R$, Nakabayashi $T$, Asao $T$, Kuwano $H$. Mechanism of gastrointestinal abnormal motor activity induced by cisplatin in conscious dogs. World J Gastroenterol 2014;20:15691-15702 [DOI: 10.3748/wjg.v20.i42.15691]

45. Horn CC. Measuring the nausea-to-emesis continuum in non-human animals: refocusing on gastrointestinal vagal signaling. Exp Brain Res 2014; 232: 2471-2481 [DOI: 10.1007/s00221-014-3985-y]

46. Roos IA, Fairlie DP, Whitehouse MW. A peculiar toxicity manifested by platinum(II)amines in rats: gastric distension after intraperitoneal administration. MWChem Biol Interact 1981;35:111-117 [DOI:10.1016/0009-2797(81)90066-1] 
47. Johnston KD, Lu Z, Rudd JA. Looking beyond 5-HT(3) receptors: a review of the wider role of serotonin in the pharmacology of nausea and vomiting. Eur $J$ Pharmacol 2014;722:13-25 [DOI: 10.1016/j.ejphar.2013.10.014]

48. Gullikson GW, Loeffler RF, Viriña MA. Relationship of serotonin-3 receptor antagonist activity to gastric emptying and motor-stimulating actions of prokinetic drugs in dogs. J Pharmacol Exp Ther 1991; 258: 103-110.

49. Hoffmann La Roche Ltd. Product monograph, PrKYTRIL®. Avalilable from

URL:http://www.rochecanada.com/content/dam/roche_canada/en_CA/do cuments/Research/ClinicalTrialsForms/Products/ConsumerInformation/M onographsandPublicAdvisories/Kytril/Kytril_PM_E.pdf

50. Huang CT, Chen CF, Tsai TH. Pharmacokinetics of granisetron in rat blood and brain by microdialysis. Life Sci 1999;64:1921-1231 [DOI:10.1016/S0024-3205(99)00143-5]

51. Obara Y, Machida T, Takano Y, Shiga S, Suzuki A, Hamaue N, lizuka K, Hirafuji M. Cisplatin increases the number of enterochromaffin cells containing substance $\mathrm{P}$ in rat intestine. Naunyn Schmiedebergs Arch Pharmacol 2018;15. [DOI: 10.1007/s00210-018-1493-5].

52. Hesketh PJ, Bohlke K, Lyman GH, Basch E, Chesney M, Clark-Snow RA, Danso MA, Jordan K, Somerfield MR, Kris MG. Antiemetics: American Society of Clinical Oncology Focused Guideline Update. American Society of Clinical Oncology. J Clin Oncol 2016;34:381-386 [DOI: 10.1200/JCO.2015.64.3635].

53. Gilmore J, D'Amato S, Griffith N, Schwartzberg L. Recent advances in antiemetics: new formulations of 5HT3-receptor antagonists. Cancer Manag Res. 2018 Jul 3;10:1827-1857. doi: 10.2147/CMAR.S166912.

54. de Wit R, van den Berg H, Burghouts J, Nortier J, Slee P, Rodenburg C, Keizer J, Fonteyn M, Verweij J, Wils J. Initial high anti-emetic efficacy of granisetron with dexamethasone is not maintained over repeated cycles. Br J Cancer 1998;77:1487-1491.

55. Margolis KG, Stevanovic K, Li Z, Yang QM, Oravecz T, Zambrowicz B, Jhaver KG, Diacou A, Gershon MD. Pharmacological reduction of 
mucosal but not neuronal serotonin opposes inflammation in mouse intestine. Gut 2014;63:928-937 [DOI: 10.1136/gutjnl-2013-304901].

56. González VM, Fuertes MA, Alonso C, Pérez JM. Is cisplatin-induced cell death always produced by apoptosis? Mol Pharmacol 2001;59:657-663. [DOl: 10.1124/mol.59.4.657]

57. Ramos JM, Arrebola F, Fernández-Cervilla FJ, Crespo V, FernándezSegura E. Electron probe X-ray microanalysis of cisplatin-induced cell death in rat pheochromocytoma $\mathrm{PC} 12$ cells. Histol Histopathol 2011;26:333-342. [DOI: 10.14670/HH-26.333].

58. Feng CC, Yan XJ, Chen X, Wang EM, Liu Q, Zhang LY, Chen J, Fang JY, Chen SL. Vagal anandamide signaling via cannabinoid receptor 1 contributes to luminal 5-HT modulation of visceral nociception in rats. Pain 2014;155(8):1591-604. [DOI: 10.1016/j.pain.2014.05.005].

59. Uranga JA, Vera G, Abalo R. Cannabinoid pharmacology and therapy in gut disorders. Biochem Pharmacol 2018; pii: S0006-2952(18)30318-6. [DOI: 10.1016/j.bcp.2018.07.048].

60. Vera G, López-Pérez AE, Uranga JA, Girón R, Martín-Fontelles MI, Abalo R. Involvement of Cannabinoid Signaling in Vincristine-Induced Gastrointestinal Dysmotility in the Rat. Front Pharmacol 2017;8:37. [DOI: 10.3389/fphar.2017.00037].

61. Panteleev SS, Martseva AA, Lyubashina OA. The inhibitory effect of granisetron on ventrolateral medulla neuron responses to colorectal distension in rats. Eur $J$ Pharmacol 2015;749:49-55. [DOI: 10.1016/j.ejphar.2015.01.002].

62. Zhang L, Song J, Hou X. Mast Cells and Irritable Bowel Syndrome: From the Bench to the Bedside. J Neurogastroenterol Motil 2016;22:181-92. [DOI: 10.5056/jnm15137].

63. Chen L, Ilham SJ, Feng B. Pharmacological Approach for Managing Pain in Irritable Bowel Syndrome: A Review Article. Anesth Pain Med 2017;7:e42747. [DOI: 10.5812/aapm.42747]. 


\section{Bedding intake}
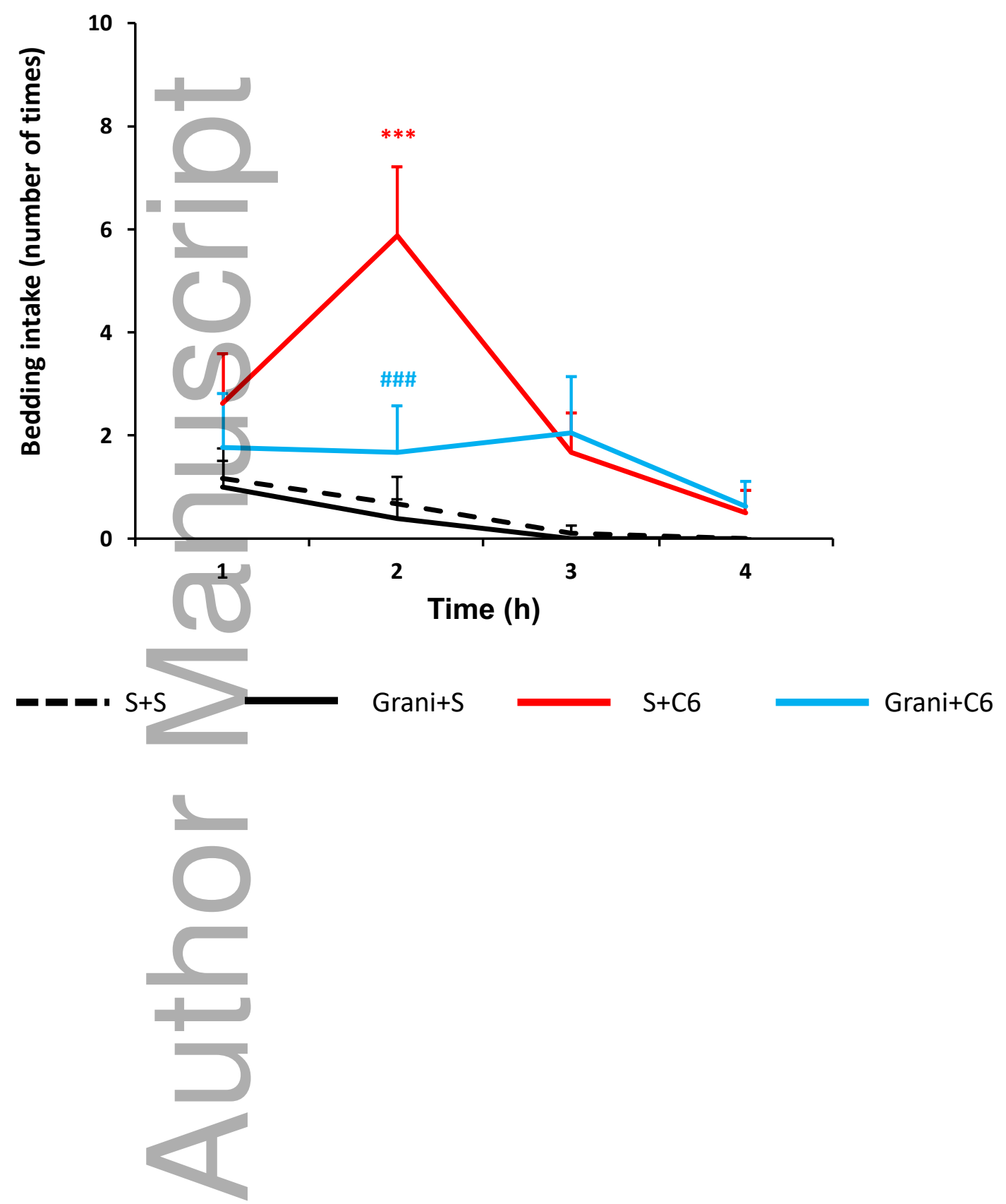

This article is protected by copyright. All rights reserved 

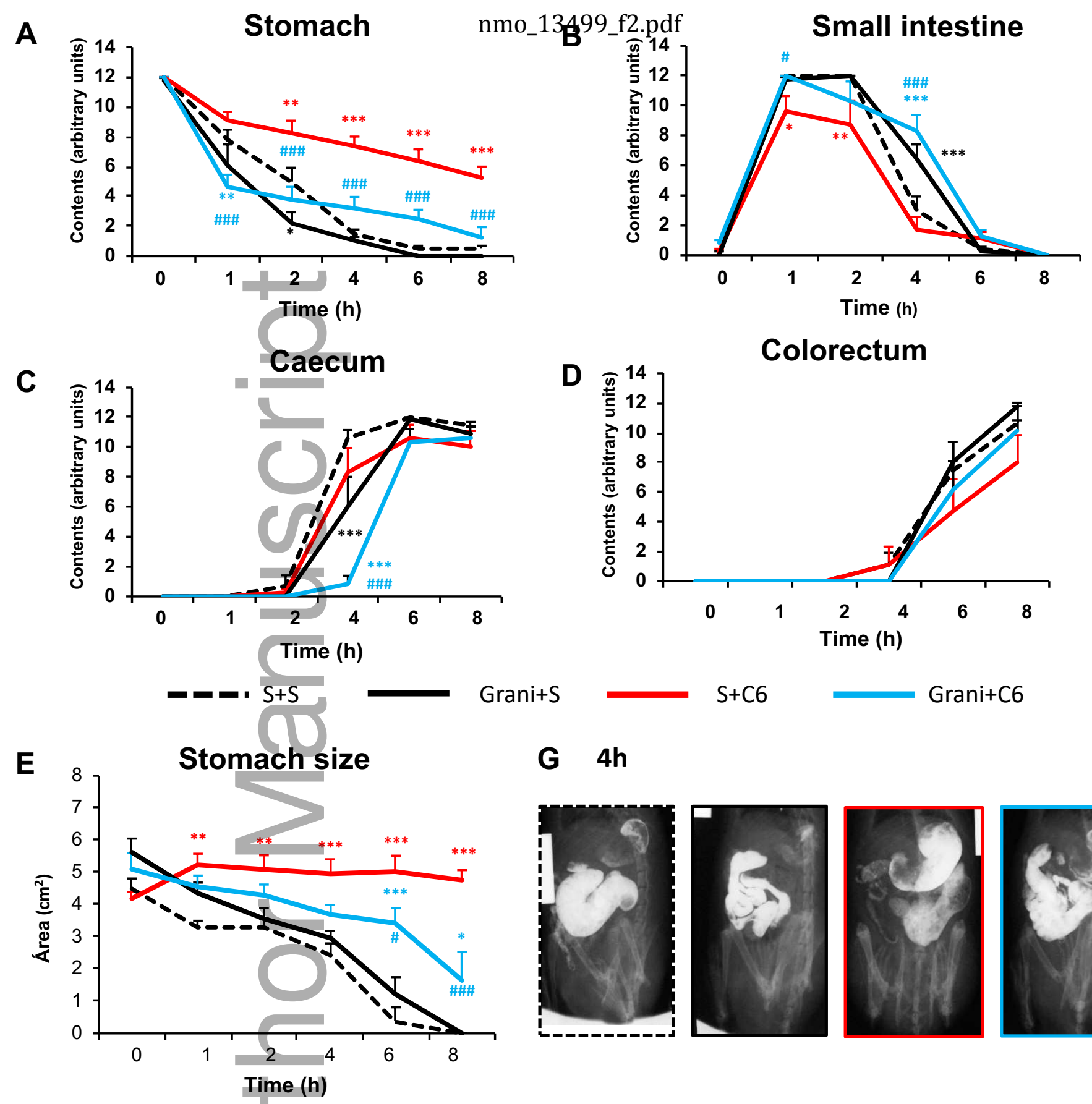

G $4 \mathrm{~h}$

$\mathbf{F}$
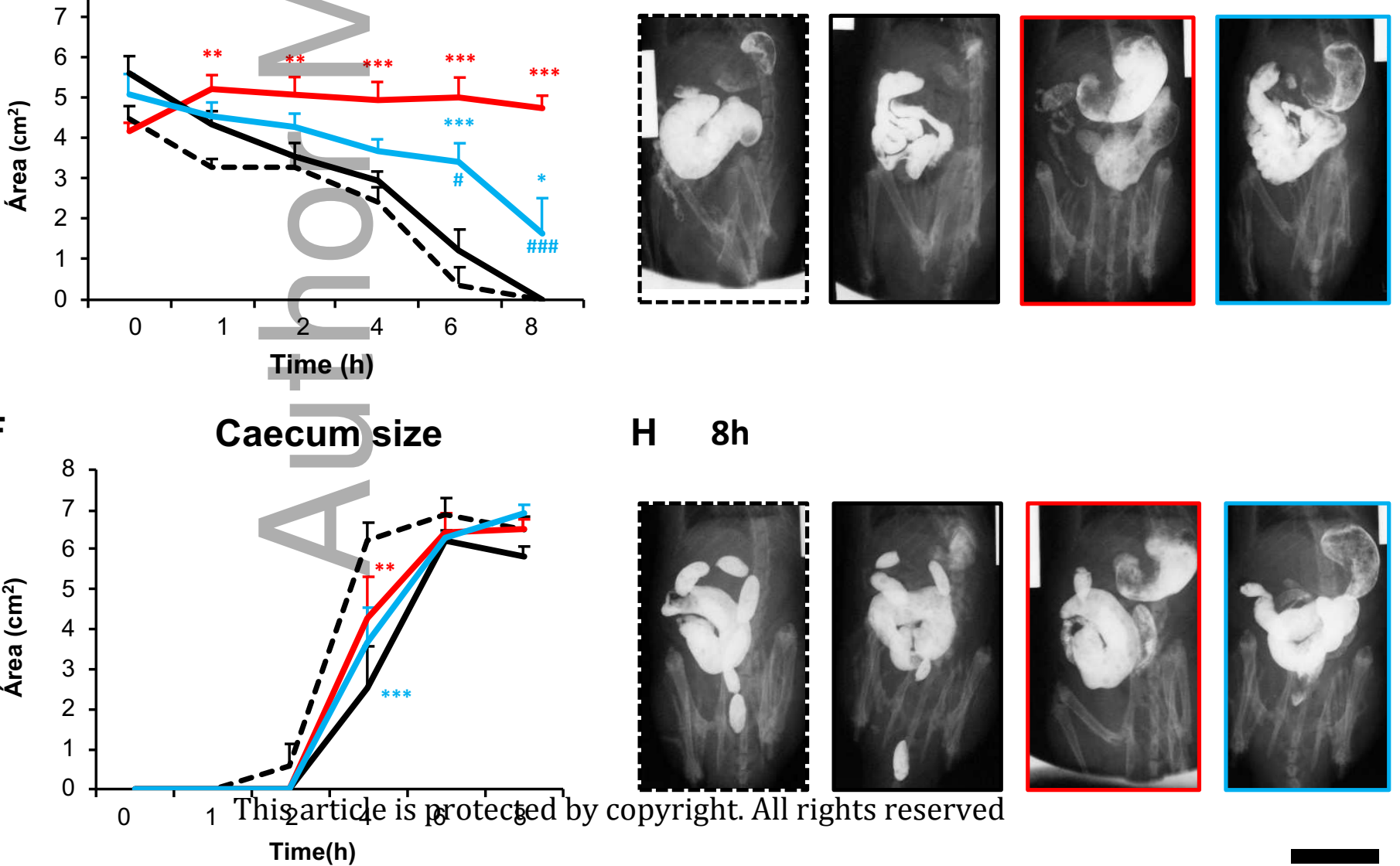
Time(h) 


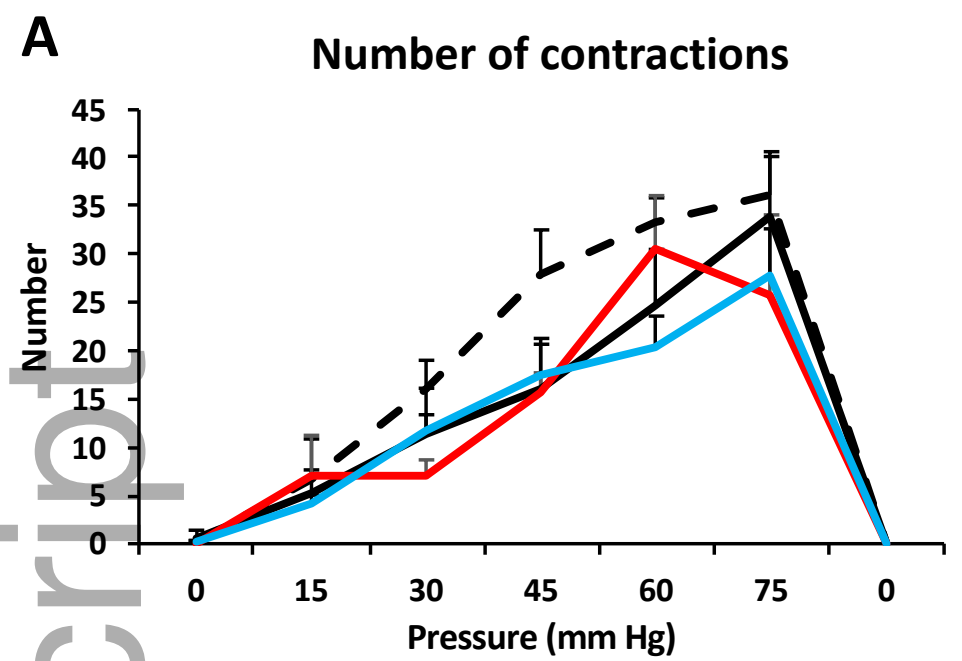

\section{B Duration of abdominal contractions}

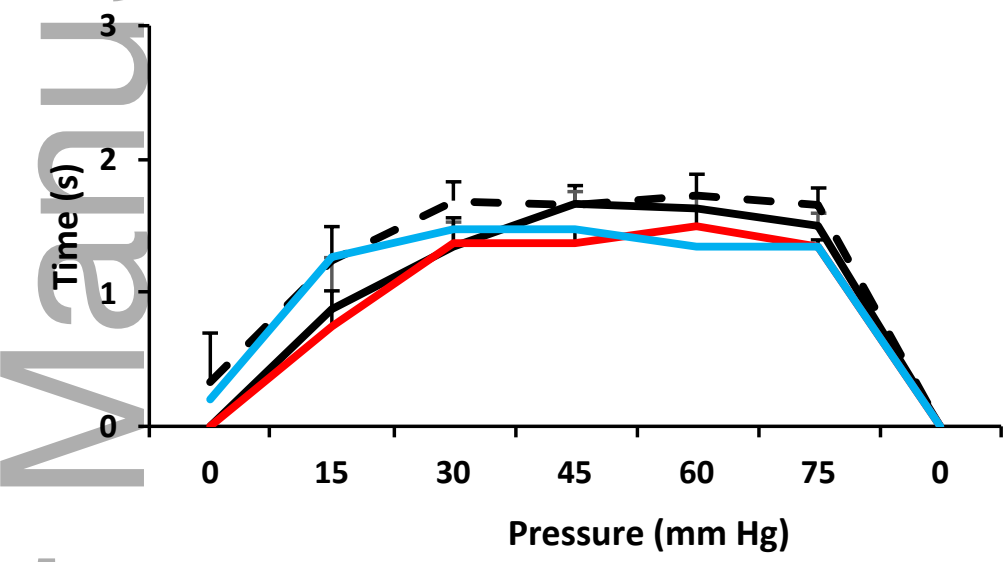

\section{C \\ $\%$ of time with abdominal contractions}

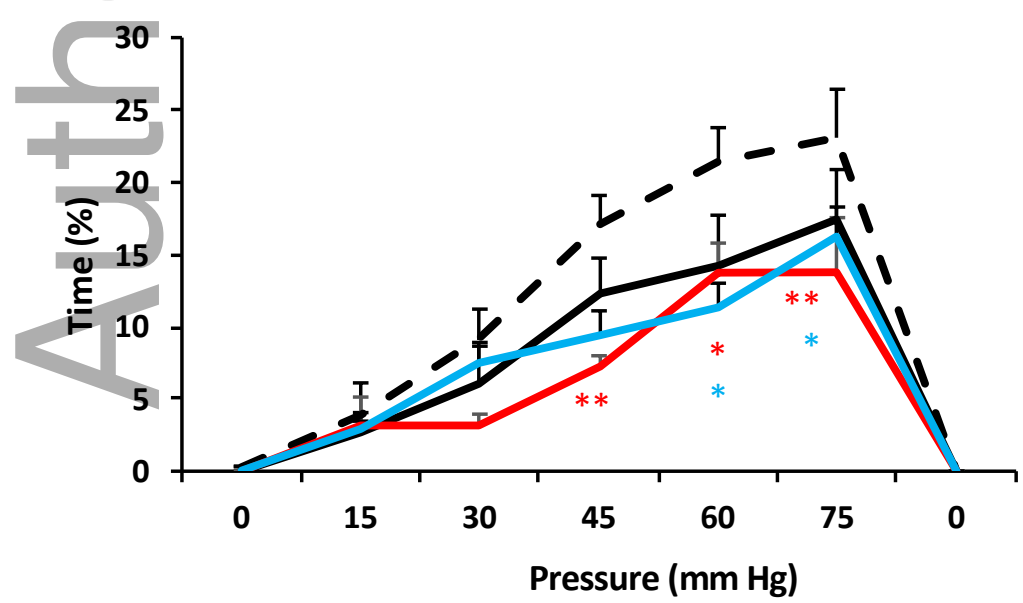

This article is protected by copyright. All rights reserved 

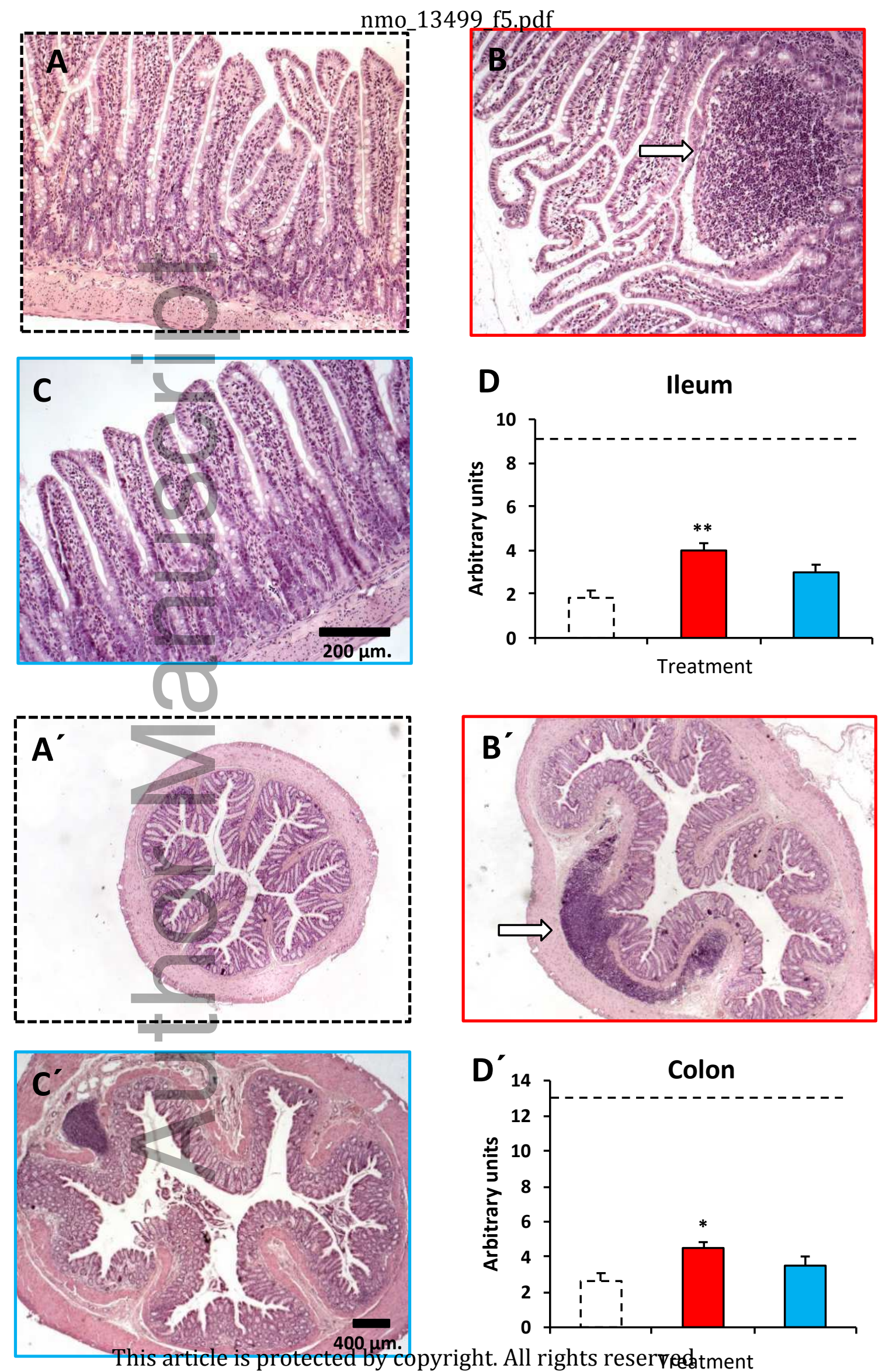

$\begin{array}{lllll}--1 & S+S \quad \square & \text { S+C6 } & \square & \text { Grani+C6 }\end{array}$ 


\section{CORPUS $(30 \mathrm{~h})$}
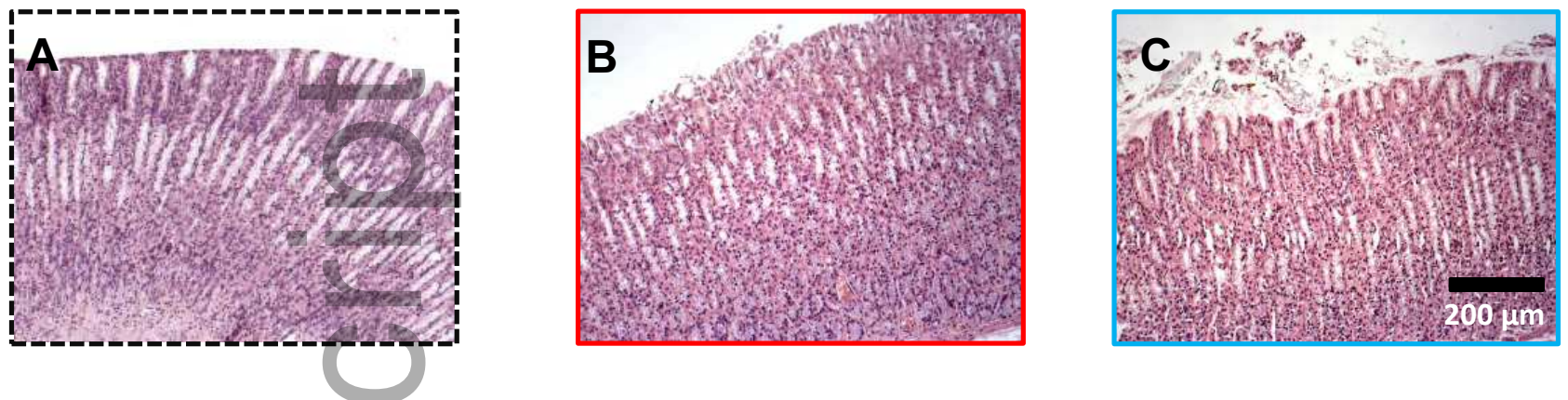

\section{FORESTOMACH $(30 \mathrm{~h})$}
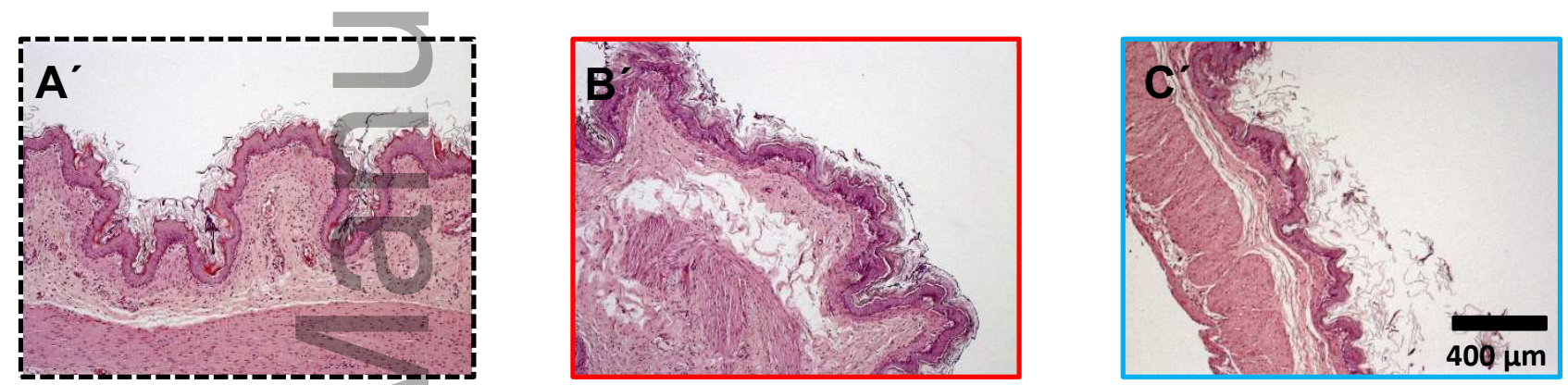

$\mathrm{S}+\mathrm{S}$

$\mathrm{S}+\mathrm{C} 6$

Grani+C6

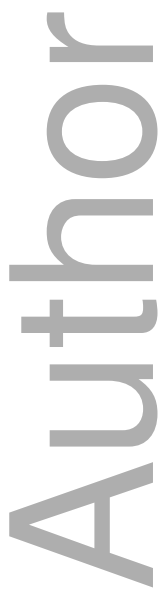

This article is protected by copyright. All rights reserved 


\section{nmo_13499_f7.pdf}
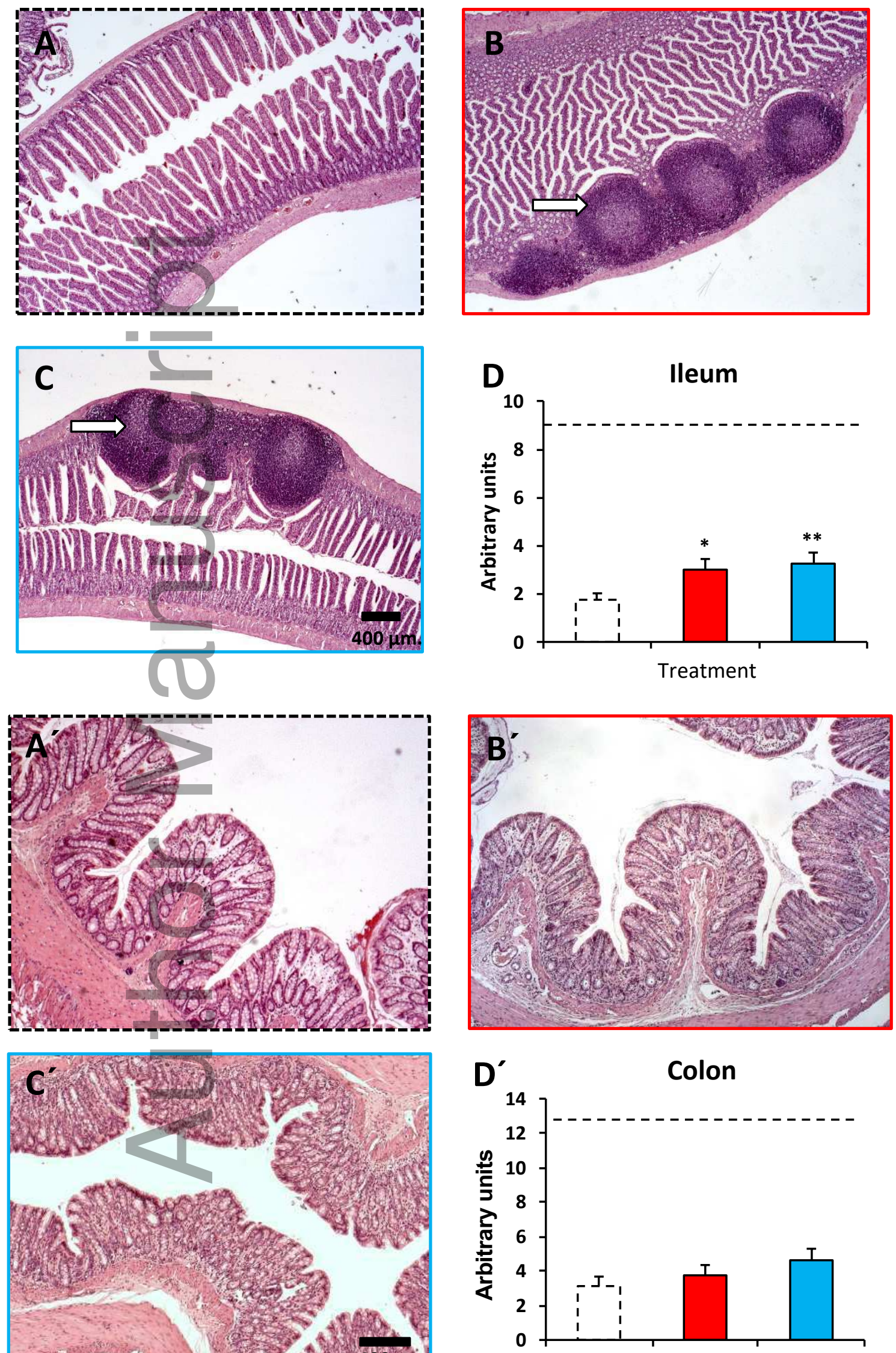

This article is protected 499 ebpyright. All rights reservedtment

$$
\begin{array}{lllll}
\mathrm{L}-1 & \mathrm{~S}+\mathrm{S} \quad & \square & \mathrm{S}+\mathrm{C} 6 \quad \square \quad & \square
\end{array}
$$




\section{University Library}

\section{- M M N E R VA A gateway to Melbourne's research publications}

Minerva Access is the Institutional Repository of The University of Melbourne

Author/s:

Martin-Ruiz, M;Uranga, JA;Mosinska, P;Fichna, J;Nurgali, K;Isabel Martin-Fontelles,

M;Abalo, R

Title:

Alterations of colonic sensitivity and gastric dysmotility after acute cisplatin and granisetron

Date:

2019-03-01

\section{Citation:}

Martin-Ruiz, M., Uranga, J. A., Mosinska, P., Fichna, J., Nurgali, K., Isabel Martin-Fontelles, M. \& Abalo, R. (2019). Alterations of colonic sensitivity and gastric dysmotility after acute cisplatin and granisetron. NEUROGASTROENTEROLOGY AND MOTILITY, 31 (3), https:// doi.org/10.1111/nmo.13499.

Persistent Link:

http://hdl.handle.net/11343/284996 